\title{
Production and Subcontracting Strategies for Manufacturers with Limited Capacity and Volatile Demand
}

\author{
Barış Tan \\ Graduate School of Business \\ Koç University \\ Rumeli Feneri Yolu, Sarıyer \\ Istanbul, Turkey \\ btan@ku.edu.tr
}

\author{
Stanley B. Gershwin \\ Department of Mechanical Engineering \\ Massachusetts Institute of Technology \\ Cambridge, Massachusetts 02139-4307 \\ USA \\ gershwin@mit.edu
}

January 28, 2003

\begin{abstract}
We study a manufacturing firm that builds a product to stock to meet a random demand. If there is a positive surplus of finished goods, customers make their purchases without delay and leave. If there is a backlog, the customers are sensitive to the quoted lead time and some choose not to order if they feel that the lead time is excessive. A set of subcontractors, who have different costs and capacities, are available to supplement the firm's production capacity. We derive a feedback policy that determines the production rate and the rate at which the subcontractors are requested to deliver products. The performance of the system, when it is managed according to this policy, is evaluated.
\end{abstract}




\section{Introduction}

$\mathrm{I}_{\mathrm{r}}^{\mathrm{N}}$

$\mathrm{N}$ many industries, companies are faced with increasing demand volatility. In this environment, retailers that adopt lean retailing practices place a larger fraction of their orders during the busy season in order to reduce the risks associated with carrying too much or too little inventory (Abernathy, Dunlop, Hammond, and Weil 1999). As a result, the retailers demand that manufacturers respond quickly to changes in customer demand. Furthermore, as competition increases, customers become more sensitive to the delivery time. Consequently, a potential customer can be lost if the lead time is too long.

In order to respond quickly to the retailer demand, a manufacturer can produce well in advance to stock or increase its capacity to reduce the lead time. Often, neither of these choices is desirable. Utilizing subcontractors can be an attractive option for manufacturers with limited capacity and volatile demand. Moreover, higher prices associated with subcontractors can be justified by reduced inventory carrying, lost sales, and markdown costs (Abernathy, Dunlop, Hammond, and Weil 2000).

The purpose of this study is to analyze the production and subcontracting strategies for a manufacturer with limited capacity and volatile lead time-dependent demand by utilizing a stochastic optimal control problem formulation. We extend the one-part-type, one-machine control problem of Bielecki and Kumar (1988). Bielecki and Kumar (1988) obtained an analytic solution to a special case of the hedging point problem of Kimemia and Gershwin (1983), in which a factory manager had to decide how to operate an unreliable machine to best satisfy a constant demand. We extend the model in three important directions.

1. Subcontractors and alternative production resources First, we provide the factory manager with external sources for the product. In this way, if demand temporarily exceeds capacity, the manager may purchase some of the product from others to reduce backlog, improve service to customers, and reduce the number of lost sales. However, this comes at a price: the profit made from purchased finished products is less than that from items produced in-house.

The same model may be used for a different purpose. This is where there are alternative production resources available within a single factory. They have different operating costs and different maximum production rates. The manager must decide which resource to use at any time.

2. Backlog and customer behavior Second, we treat backlog in a more fundamental way than Kimemia and Gershwin (1983), Bielecki and Kumar (1988), or any of the subsequent papers that refined or extended their models of real-time scheduling of manufacturing systems. In these papers, the difference between cumulative production and cumulative demand is called surplus, and is usually represented by $x$. When $x$ is negative, it is backlog. The performance objective to be minimized is a function of $x$, which increases as $x$ deviates from 0 , for both $x$ positive and $x$ negative. In this way, the optimization tends to keep $x$ near 0 .

This makes economic sense for $x>0$. In that case, $x$ is finished goods inventory, and there are clear, tangible costs associated with inventory (including the interest cost on the raw material, the floor space devoted to storage, etc.). However, there is no such tangible cost associated with 
backlog. The undesirable consequence of backlog is the loss of sales, and lost sales are not related to backlog by a simple quantitative relationship.

Here, instead of including an explicit cost term for $x<0$, we model the response of potential customers to backlogs. In this model, if there is a positive surplus of finished goods, the customers make their purchases without delay and leave. If there is a backlog, some fraction of the customers are willing to wait to make their purchases, but others depart in disgust. The greater the backlog, the more customers leave without making a purchase.

The reason for avoiding backlog comes from the fact that some potential customers choose not to place orders, and such lost sales reduce revenues. In this way, we replace an artificial, contrived cost term with a more natural model of the phenomenon that causes the cost.

3. Reliable supply and variable demand We assume a perfectly reliable factory and perfectly reliable subcontractors. Randomness in the model comes from the variability of the demand. Customers arrive at the factory at rate $d$, which is either high $\left(d=\mu_{\mathrm{H}}\right)$ or low $\left(d=\mu_{\mathrm{L}}\right)$. The transitions from high to low and low to high occur at exponentially distributed time instants.

The second and third items were introduced in a model without subcontractors in Gershwin and $\operatorname{Tan}(2001)$.

The problem we solve is: How do we operate our manufacturing plant, and how do we use subcontractors, to maximize profit? Profit is revenue minus cost; the revenues are diminished by customers who defect rather than wait when they see a backlog. The cost, which is due only to holding inventory, is nonzero only when the surplus is positive.

A special case of the customer behavior is the lost sales case, in which customers choose not to place orders whenever there is any backlog. Another special case of the model is where the firm does no manufacturing of its own, and only uses subcontractors.

We only consider the effect of backlog on present sales. We do not consider the fact that a customer who finds the backlog too great is less likely to attempt to make a purchase in the future; and we do not consider the damage to a firm's reputation when it has frequent large backlogs.

We form a dynamic programming problem which is similar to that of Bielecki and Kumar (1988), except that there is no cost for backlog in the objective function. Instead, the objective function rewards revenues and penalizes cost, which is due only to inventory. The revenues are greatest for products manufactured in-house, and less for those provided by subcontractors. Revenues are also diminished by the defection of potential customers who are not willing to wait for their products.

We use the Bellman equation to determine the structure of the solution. We find that it is a generalization of the hedging point policy of Kimemia and Gershwin (1983), Bielecki and Kumar (1988), and Gershwin and Tan (2001). The hedging point is a threshold indicating when there is sufficient surplus, and there are additional thresholds to indicate when to use each of the subcontractors.

To determine the optimal values of these thresholds, we derive the differential equations for the density function of the surplus. These equations can be solved analytically when $B(x)$ is piecewise constant. Since we can approximate any $B(x)$ with a piecewise constant function, we can therefore solve systems with essentially any $B(x)$. We express the solution as a function of the thresholds. Finally, we optimize over the thresholds. 


\section{Past Work}

Since the 1980s, there has been an increasing interest in devising optimal production control policies that manage production in uncertain environment. An optimal flow-rate control problem for a failure prone machine subject to a constant demand source was introduced by Olsder and Suri (1980) and Kimemia and Gershwin (1983). The single-part-type, single-machine problem was analyzed in detail by Bielecki and Kumar (1988). The optimal control is a hedging point policy where the machine operates at its maximum rate until the inventory reaches a certain level; and then it operates at a rate that keeps the inventory at this level. Hedging point control policies are optimal or near optimal for a range of manufacturing system models. Hedging policies have been shown to be effective in a manufacturing environment by Yan, Lou, Sethi, Gardel, and Deosthali (1996). Most of these studies assume a constant demand source. Only a few consider optimal production control problems with random demand, including Fleming, Sethi, and Soner (1987), Ghosh, Araposthathis, and Markus (1993), Tan (2002b), and Perkins and Srikant (2001). For an overview of the dynamic programming formulations of factory scheduling and inventory control and a comprehensive list of references, see Gershwin (1994).

The extension of the problem for an unreliable machine with constant demand and a single contractor whose capacity is high enough to meet the demand was investigated by Gershwin (1993). He conjectured the optimality of the hedging policy. The optimality of this policy is proven by Huang, $\mathrm{Hu}$, and Vakili (1999). A simpler version of this problem where backlog is not permitted and the subcontractor with sufficient capacity is used when the inventory level is zero was analyzed by $\mathrm{Hu}$ (1995). Tan (2002a) utilizes an extension of this model with variable demand and reliable production to study capacity options.

The problem of controlling a machine that can produce at a fixed rate to meet random demand is presented by Krichagina, Lou, and Taksar (1994). In this study, whenever the machine stops, a setup is performed to start production again. Moreover, backlogging is not allowed and a subcontractor can be used by paying a fixed cost and a variable cost. By using a Brownian approximation of the model, it is shown that the optimal policy is characterized by three parameters and referred as a double-band policy.

A two-period competitive stochastic investment game is presented by Van Mieghem (1999). In this model, the manufacturer and subcontractor decide on their capacity investment levels separately in the first period. After the demand uncertainty is resolved in the second period, both parties decide on their production and sales with the option to subcontract. The value of the option of subcontracting is determined is then determined by using this model.

A Brownian motion approximation for the optimal subcontracting policy for an $M / M / 1$ system is given by Bradley (1999). This problem is extended by Bradley and Glynn (2000a) by optimizing the capacity, inventory, and subcontracting jointly. Competition and coordination issues in this model are addressed by Bradley and Glynn (2000b) by focusing on a multi-stage game where the equilibrium is computed by using the Brownian approximation.

For a number of discrete-time inventory models with two sources, a dual base-stock policy, with parameters $s_{1}$ and $s_{2}$, is shown to be optimal. In this policy, the first source, the manufacturer, is used when the inventory falls below $s_{1}$ and the second source, the subcontractor, is used when 
the inventory falls below $s_{2}$. See Fukuda (1964), Whittemore and Saunders (1977), Zhang (1995). The same policy is shown to be optimal for a continuous time $M / M / 1$ system with average cost criterion by Bradley (1999).

In a different context, the problem of managing a number of power generators with different costs and capacities is studied by Schweppe, Caramanis, Tabors, and Bohn (1988). They show that the power generators are used in order of increasing per unit production cost when the marginal cost of losing the demand is higher than the marginal cost of receiving the energy from that source. Since the electrical energy cannot be stored or backlogged, this problem is a special case of the problem studied here.

The pertinent literature on models with lead-time sensitive customers can be found in Gershwin and Tan (2001). Gershwin and Tan (2001) also gives the complete solution for the production control problem of a single manufacturing facility without subcontractors and with volatile demand.

The model description and its assumptions are given in Section 3. The general solution structure is derived in Section 4. The model is analyzed and the steady state probability distributions are formulated in Section 5. Section 6 describes the evaluations of the objective function and of other performance measures of interest. Section 8 contains a summary of the paper and several proposed research directions.

\section{Model with Subcontracting}

Someday, and that day may never come, I will call upon you to do a service for me. But until that day, accept this ... gift .... (Puzo 1969)

In this section, we present the assumptions of the model and introduce subcontractors. The manufacturing plant and each of the $K$ subcontractors have a capacity - a maximum rate at which it can deliver. It also has a price that it will sell the goods at. We are not concerned here with that price; instead, we need to know the profit that the firm can earn by reselling each item. We assume that the profit from reselling is less than that from the manufacturer's own production facilities. The optimal policy of setting the production rate of the manufacturing plant and deciding on the rate at which the each subcontractor provides additional capacity is derived in Section 4.

\subsection{Basic Model}

We consider a make-to-stock system consisting of a single manufacturing facility and $K$ subcontractors that produces to meet the demand for a single item. Production, demand, inventory, and backlog are all represented by continuous (real) variables. The demand rate at time $t$ is denoted by $d(t)$. The state of the demand at time $t$ is $D(t)$ which is either high $(\mathrm{H})$ or low $(\mathrm{L})$. When the demand is high, the demand rate is $d(t)=\mu_{\mathrm{H}}$ and when the demand is low, the demand rate is $d(t)=\mu_{\mathrm{L}}$. At time $t$, the amount of finished goods inventory or backlog is $x(t)$.

The times to switch from a high demand state to a low demand state and from a low demand state to a high demand state are assumed to be exponentially distributed random variables with rates $\lambda_{\mathrm{HL}}$ and $\lambda_{\mathrm{LH}}$. This model is suitable for describing demand which is stationary in the long 
run, but whose mean shifts temporarily as a result of promotions, competitor actions, etc. The time since the last state change does not change the expected time until the next state change. The average demand rate is

$$
E d=\mu_{\mathrm{H}} e+\mu_{\mathrm{L}}(1-e)
$$

where

$$
e=\frac{\lambda_{\mathrm{LH}}}{\lambda_{\mathrm{HL}}+\lambda_{\mathrm{LH}}}
$$

is the percentage of the time the demand is high.

The total amount demanded during a period of length $t$, from this model, is asymptotically normal as $t \rightarrow \infty$ and the limiting variance rate of the amount demanded during a period of length $t$ is given by (Tan 1997) as

$$
V d=\lim _{t \rightarrow \infty} \frac{\operatorname{Var}[N(t)]}{t}=\frac{2\left(\mu_{\mathrm{H}}-\mu_{\mathrm{L}}\right)^{2}(1-e) e^{2}}{\lambda_{\mathrm{LH}}}
$$

The asymptotic coefficient of variation of the demand, defined as $c v=\sqrt{V d} / E d$, is used as a summary measure of the demand variability in this study. Here, it is given by

$$
c v=\sqrt{\frac{\mu_{\mathrm{H}}-\mu_{\mathrm{L}}}{\lambda_{\mathrm{LH}} \mu_{\mathrm{H}}+\lambda_{\mathrm{HL}} \mu_{\mathrm{L}}}\left(\frac{1}{\lambda_{\mathrm{HL}}}+\frac{1}{\lambda_{\mathrm{LH}}}\right)^{-1}}
$$

The profit coefficient (dollars per unit) for the goods produced in the factory is $A_{0}$ and the profit coefficient (dollars per unit) when subcontractor $i$ is used is $A_{i}$. The factory and the subcontractors are indexed in decreasing $A_{i}$, i.e., $A_{0}>A_{1}>A_{2}>A_{3}>\ldots>A_{K}>0$. That is, production source $i+1$ is less desirable to use than production source $i$ because it is more expensive, and therefore results in less profit. The same model can be used for a single subcontractor that offers piecewise linear convex cost structure by modeling each term in the cost function as a separate subcontractor.

The inventory carrying cost is $g^{+}$(dollars per unit per time). As indicated earlier, we do not include the corresponding backlog cost $g^{-}$, which does appear in Bielecki and Kumar (1988) and many other papers.

At time $t$, the plant produces finished goods at rate $u_{0}(t)$, and requests subcontractor $i$ to supply materials at a rate of $u_{i}(t), 0 \leq u_{i}(t) \leq \underline{u}_{i} . u_{i}(t), i=0,1, \ldots, K$ are the decision variables of the production control problem. The subcontractors are perfectly reliable and they deliver instantaneously. We do not make any assumptions regarding the capacities $\underline{u}_{i}$ of the subcontractors.

\subsection{Backlog-Dependent Demand}

When there is backlog (i.e., when $x<0$ ), a potential customer chooses not to order with probability $B(x)$ when the backlog is $x$. (Alternatively, $B(x)$ is the fraction of potential customers who choose 
not to order when the backlog is $x$.) $B(x)$, which is called the defection function, satisfies

$$
\left.\begin{array}{l}
0 \leq B(x) \leq 1, \\
x \geq 0 \Longrightarrow B(x)=0, \\
x<0 \Longrightarrow B(x)>0,
\end{array}\right\}
$$

The first condition is required by the definition of $B$ as a probability or a fraction. The second says that no potential customers are motivated to defect when there is surplus. The third says that there are always some potential customers that refuse to wait if there is a backlog.

If $B(x)$ satisfies

$$
B(x) \text { is a non-increasing function of } x,
$$

we say that $B$ is a monotonic defection function. If $B$ is monotonic, more customers are impatient if there is a longer wait. In the following, we restrict our attention to monotonic defection functions.

Note that $B(x)=1$ for all $x<0$ corresponds to the lost sales case. In this situation, no customers are willing to wait to receive their goods. All revenues are lost whenever there is any backlog.

Now, when the surplus level is $x<0$, the time until the next arriving customer order will be completed, i.e., the production lead time, is no greater than $-x / \underline{u}_{0}$. This is the time to clear the current backlog if no subcontractors are used. The lead-time dependent demand case can therefore be treated by using $B(x)=\tilde{B}\left(\underline{u}_{0} \tau\right)$ as the probability that a potential customer chooses not to order when the quoted guaranteed lead time is $\tau=-x / \underline{u}_{0}$. A sharper bound can be developed if we assume a specific production and backlog policy, for example that of Section 4.

Combining the backlog-dependent demand rate and subcontracting, the dynamics of $x$ are given by

$$
\frac{d x}{d t}=\sum_{i=0}^{K} u_{i}-d(1-B(x))
$$

\subsection{Production Control Problem}

The decision variables are the rate at which the goods are produced at the plant at time $t, u_{0}(t)$, and the rates at which the subcontractors are requested to supply goods at time $t, u_{i}(t) i=$ $1,2, \ldots, K$. The profit function to be maximized is the difference between the profit generated through production and subcontracting and the inventory carrying costs. A linear inventory carrying cost function is assumed, i.e.,

$$
g(x)=\left\{\begin{array}{l}
g^{+} x \text { if } x \geq 0 \\
0 \text { if } x<0
\end{array}\right.
$$

The production control problem is 


$$
V=\max _{u_{0}, u_{1}, \ldots, u_{K}} \Pi=E \int_{0}^{T}\left(\sum_{i=0}^{K} A_{i} u_{i}-g(x)\right) d t
$$

subject to

$$
\begin{gathered}
\frac{d x}{d t}=\sum_{i=0}^{K} u_{i}-d(1-B(x)) \\
0 \leq u_{i} \leq \underline{u}_{i} \quad i=0,1, \ldots, K \\
d=\left\{\begin{array}{lll}
\mu_{\mathrm{H}} & \text { if } & D=\mathrm{H} \\
\mu_{\mathrm{L}} & \text { if } & D=\mathrm{L}
\end{array}\right.
\end{gathered}
$$

We do not include an explicit cost for backlog in the definition of $g$. Instead, we are penalized for backlog by the defection of impatient customers and the reduced profits due to the use of subcontractors.

We do not need to assume that the demand is feasible. If $E d$ is greater than $u_{0}$, some subcontracting will certainly be used. If $E d$ is greater than the total capacity $\sum_{i=0}^{K} \underline{u}_{i}$ then enough impatient customers will defect to guarantee that $x$ is bounded from below.

We assume that $T$ is very large, so the optimal policy discussion in Section 4 is based on the assumption that the probability distribution of $(x, D)$ reaches a steady state.

\section{Characterization of the Policy with Subcontractors}

Problem (4)-(8) is a dynamic programming problem. The solution (the optimal rates of production as functions of $x, D$, and $t$ ) satisfies the Bellman equation. In this section, we use the Bellman equation to determine the structure of the solution. For more information about the Bellman equation and the maximum principle that is utilized in the derivation, the reader is referred to (Sethi and Thompson 2000).

\subsection{Bellman equation}

The value function is defined as:

$$
V(x(t), D(t), t)=E \int_{t}^{T}\left(-\sum_{i=0}^{K} A_{i} u_{i}+g(x)\right) d \tau
$$

$V$ satisfies the maximum principle, which asserts that 


$$
\begin{gathered}
-\frac{\partial V}{\partial t}(x, \mathrm{~L}, t)=\min _{u_{0}, u_{1}, \ldots, u_{K}}\left\{-\sum_{i=0}^{K} A_{i} u_{i}+g(x)+\frac{\partial V}{\partial x}(x, \mathrm{~L}, t)\left(\sum_{i=0}^{K} u_{i}-\mu_{\mathrm{L}}(1-B(x))\right)\right. \\
\left.+V(x, \mathrm{H}, t) \lambda_{\mathrm{HL}}-V(x, \mathrm{~L}, \mathrm{t}) \lambda_{\mathrm{HL}}\right\}
\end{gathered}
$$

for $D=\mathrm{L}$, and

$$
\begin{gathered}
-\frac{\partial V}{\partial t}(x, \mathrm{H}, t)=\min _{u_{0}, u_{1}, \ldots, u_{K}}\left\{-\sum_{i=0}^{K} A_{i} u_{i}+g(x)+\frac{\partial V}{\partial x}(x, \mathrm{H}, t)\left(\sum_{i=0}^{K} u_{i}-\mu_{\mathrm{H}}(1-B(x))\right)\right. \\
\left.+V(x, \mathrm{~L}, t) \lambda_{\mathrm{LH}}-V(x, \mathrm{H}, t) \lambda_{\mathrm{LH}}\right\}
\end{gathered}
$$

for $D=\mathrm{H}$. The minimizations are taken over constraints (6).

It is reasonable to assume, since $V$ is the solution of a dynamic programming problem, that $V$ is strictly convex in $x$. The convexity of $V$ was proven for a related problem by (Huang, $\mathrm{Hu}$, and Vakili 1999). The formal proof of the convexity of $V$ is not given in this study. Since $V$ is assumed to be strictly convex, it has a unique minimum. If that minimum were not finite, $x$ would be increasing or decreasing without bound. If $x$ were increasing without bound, (9) implies that $V$ is infinite, and this cannot be optimal. It is not possible for $x$ to decrease without bound because $B(x)$ increases with decreasing $x$, and there is a value of $x$ below which $d x / d t(3)$ must be zero or positive. Therefore $V$ has a finite minimum. Figure 1 shows $V$ as a function of $x$ when $d=\mu_{\mathrm{L}}$ and we assume that $V$ is continuously differentiable. The graph of $V$ when $d=\mu_{\mathrm{H}}$ is similar.

From (10) and (11), for both values of $D$,

$$
u_{i}^{*}(x, D)=\left\{\begin{array}{ccc}
0 & \text { if } & -A_{i}+\frac{\partial V}{\partial x}(x, D)>0 \\
\text { undetermined } & \text { if } & -A_{i}+\frac{\partial V}{\partial x}(x, D)=0 \\
\underline{u}_{i} & \text { if } & -A_{i}+\frac{\partial V}{\partial x}(x, D)<0
\end{array}\right.
$$

for $i=0,1, \ldots, K$.

\section{$4.2 \quad D=\mathrm{L}$}

(12) says that if $d=\mu_{\mathrm{L}}, u_{0}=\underline{u}_{0}$ if $-A_{0}+\partial V / \partial x<0$. Since $V$ is convex with a finite minimum, that will occur for all $x$ less than some value which we call $Z_{0}(\mathrm{~L})$. Conversely, $u_{0}=0$ for $x>Z_{0}(\mathrm{~L})$.

Similarly, for each $i,(12)$ implies that there is a value of $x$, called $Z_{i}(\mathrm{~L})$, such that $-A_{i}+$ $\partial V / \partial x<0$ for $x<Z_{i}(\mathrm{~L})$ and $-A_{i}+\partial V / \partial x>0$ for $x>Z_{i}(\mathrm{~L})$. Consequently $u_{i}=\underline{u}_{i}$ for 


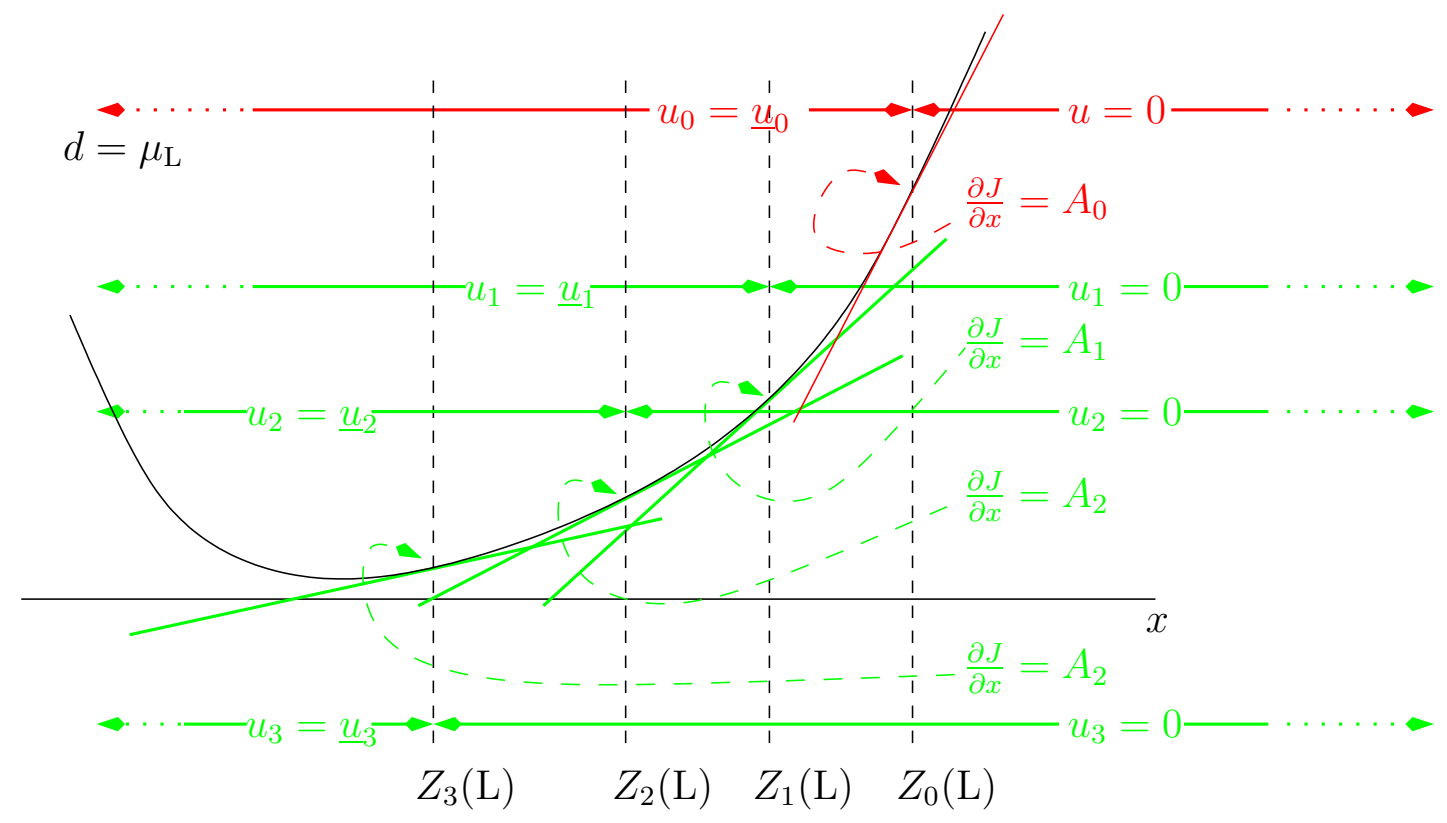

Figure 1: $V$ vs. $x, d=\mu_{\mathrm{L}}$

$x<Z_{i}(\mathrm{~L})$ and $u_{i}=0$ for $x>Z_{i}(\mathrm{~L})$. Since $A_{0}>A_{1}>A_{2} \ldots>A_{K}$ and since $V$ is strictly convex, $Z_{0}(L)>Z_{1}(\mathrm{~L})>Z_{2}(\mathrm{~L})>\ldots>Z_{K}(\mathrm{~L})$.

Consequently,

- When $x>Z_{0}(\mathrm{~L}), \quad u_{i}=0, i=0,1, \ldots, K$.

- When $Z_{1}(\mathrm{~L})<x<Z_{0}(\mathrm{~L}), \quad u_{0}=\underline{u}_{0}$ and $u_{i}=0, i=1, \ldots, K$.

- When $Z_{2}(\mathrm{~L})<x<Z_{1}(\mathrm{~L}), \quad u_{0}=\underline{u}_{0}, u_{1}=\underline{u}_{1}$, and $u_{i}=0, i=2, \ldots, K$.

- When $Z_{3}(\mathrm{~L})<x<Z_{2}(\mathrm{~L}), \quad u_{0}=\underline{u}_{0}, u_{1}=\underline{u}_{1}, u_{2}=\underline{u}_{2}$, and $u_{i}=0, i=3, \ldots, K$.

- etc.

When $x=Z_{0}(\mathrm{~L})$ and $D=\mathrm{L}$, we already know that $u_{1}=u_{2}=\ldots=u_{K}=0$. Therefore, from $(3)$,

$$
\frac{d x}{d t}=u_{0}-\mu_{\mathrm{L}}\left(1-B\left(Z_{0}(\mathrm{~L})\right)\right)
$$

Recall that we have assumed that $\underline{u}_{0}>\mu_{\mathrm{L}}$. Therefore the right side of (14) could be positive (as well as negative). If $u_{0}>\mu_{\mathrm{L}}\left(1-B\left(Z_{0}(\mathrm{~L})\right)\right)$, then (14) implies that $x$ will increase and therefore we will soon have $x>Z_{0}(\mathrm{~L})$. At that point, $u_{0}$ will immediately become 0 and $x$ will decrease. After 
a very short time, $x<Z_{0}(\mathrm{~L})$ so $u_{0}=\underline{u}_{0}$ and $x$ will increase again. Consequently, $u_{0}$ will jump infinitely rapidly (in an idealized mathematical model) between 0 and $\underline{u}_{0}$ and $x$ will remain very close to $Z_{0}(\mathrm{~L})$. (Similar behavior results if we let $u_{0}<\mu_{\mathrm{L}}\left(1-B\left(Z_{0}(\mathrm{~L})\right)\right)$.) To avoid this undesirable and unnecessary chattering, we choose $u_{0}=\mu_{\mathrm{L}}\left(1-B\left(Z_{0}(\mathrm{~L})\right)\right.$ when $x=Z_{0}(\mathrm{~L})$. Note also that since $d x / d t=0, x$ remains at $Z_{0}(\mathrm{~L})$ until $d$ changes to $\mu_{\mathrm{H}} . Z_{0}(\mathrm{~L})$ is therefore a hedging point.

Since $x$ can remain at $Z_{0}(\mathrm{~L})$ indefinitely with no subcontracting, it is not likely that $Z_{0}(\mathrm{~L})<0$. When $x<0$, sales are lost, and there is no offsetting benefit. We can therefore assume that $Z_{0}(\mathrm{~L}) \geq 0$ and that $u_{0}\left(Z_{0}(\mathrm{~L}), \mathrm{L}\right)=\mu_{\mathrm{L}}$.

No such issue occurs for any other $Z_{i}(\mathrm{~L})$. This is because the dynamics in the vicinity of $x=Z_{i}(\mathrm{~L})$ are

$$
\frac{d x}{d t}=\left\{\begin{array}{l}
\sum_{j=0}^{i-1} \underline{u}_{j}-\mu_{\mathrm{L}}(1-B(x)) \text { for } x>Z_{i}(\mathrm{~L}) \\
\sum_{j=0}^{i} \underline{u}_{j}-\mu_{\mathrm{L}}(1-B(x)) \text { for } x<Z_{i}(\mathrm{~L})
\end{array}\right.
$$

Since $\underline{u}_{0}>\mu_{\mathrm{L}}$ and $\underline{u}_{j}>0$, the right side of (15) is always positive, regardless whether $x<Z_{i}(\mathrm{~L})$ or $x>Z_{i}(\mathrm{~L})$. Consequently, there is no possibility of chattering at $x=Z_{i}(\mathrm{~L}), i>0$.

To summarize, the trajectory behaves as follows when $D=\mathrm{L}$ :

- If $x>Z_{0}(\mathrm{~L})$, all rates are 0 and $x$ decreases at rate $-\mu_{\mathrm{L}}$ until it reaches $Z_{0}(\mathrm{~L})$.

- If $x=Z_{0}(\mathrm{~L}), u_{0}=\mu_{\mathrm{L}}$ and $x$ remains constant.

- If $Z_{i}(\mathrm{~L}) \leq x<Z_{i-1}(\mathrm{~L}), u_{j}=\underline{u}_{j}$ for $j=0, \ldots, i-1 . x$ increases at rate $\underline{u}_{0}+\underline{u}_{1}+\underline{u}_{2}+\ldots+\underline{u}_{i-1}$ until $x=Z_{i-1}(\mathrm{~L})$.

\section{3 $D=\mathbf{H}$}

The behavior when $d=\mu_{\mathrm{H}}$ is determined by the same considerations as when $d=\mu_{\mathrm{L}}$, but it is not the same. Equation (3) becomes, at $x=Z_{0}(\mathrm{H})$,

$$
\frac{d x}{d t}=u_{0}-\mu_{\mathrm{H}}\left(1-B\left(Z_{0}(\mathrm{H})\right)\right)
$$

Since $\underline{u}_{0}<\mu_{\mathrm{H}}$, the right side is guaranteed to be negative unless $Z_{0}(\mathrm{H})<0$. But $Z_{0}(\mathrm{H})<0$ cannot be optimal because if $x>Z_{0}(\mathrm{H}), u_{0}=u_{1}=u_{2}=\ldots=u_{K}=0 . x$ will decrease at the maximum possible rate $\left(-\mu_{\mathrm{H}}\left(1-B\left(Z_{0}(\mathrm{H})\right)\right)\right)$, and there will be no revenues. While this may be beneficial if $x>0$ because it reduces inventory cost, it cannot be beneficial if $0>x>Z_{0}(\mathrm{H})$ because some customers (who would bring future revenues) choose not to order. As $Z_{0}(\mathrm{H})$ increases toward 0 , fewer and fewer such future sales are lost. Therefore $Z_{0}(\mathrm{H}) \geq 0$.

Consequently, since the right side of $(16)$ is always negative, $Z_{0}(\mathrm{H})$ is not a hedging point (or any other kind of temporary equilibrium), so if $x$ is ever near this value, it must decrease. As 
$x$ decreases past $Z_{1}(\mathrm{H}), Z_{2}(\mathrm{H})$, etc., the right side of $(3)$ increases (i.e., the rate of decrease of $x$ diminishes), because $B(x)$ increases, and because more and more subcontractors are used, until one of two events occurs. Either

1. Enough $(i)$ subcontractors are engaged to satisfy

$$
\sum_{j=0}^{i} \underline{u}_{j}>\mu_{\mathrm{H}}\left(1-B\left(Z_{i}(\mathrm{H})\right)\right)
$$

Then we choose $u_{0}=\underline{u}_{0}, u_{j}=\underline{u}_{j}($ for $j<i)$, and $u_{i}=u_{i}^{*}$, where

$$
\sum_{j=0}^{i-1} \underline{u}_{j}+u_{i}^{*}=\mu_{\mathrm{H}}\left(1-B\left(Z_{i}(\mathrm{H})\right)\right) ;
$$

and $x$ remains constant, equal to $Z_{i}(\mathrm{H})$;

or

2. The rate of order loss $B(x)$ increases enough so that the right side of (3) becomes equal to zero for some $x^{*}$ which is not equal to any $Z_{j}(\mathrm{H})$. That is,

$$
\sum_{j=0}^{i} \underline{u}_{j}=\mu_{\mathrm{H}}\left(1-B\left(x^{*}\right)\right)
$$

In both cases, $x$ has reached a lower limit, since $d x / d t$ has reached 0 . (In the latter case, $x$ may approach the lower limit asymptotically, for suitable $B(x))$.$x remains at this level until the demand$ changes and $D=\mathrm{L}$. At that point, the behavior described in Section 4.2 resumes. It is convenient to define $\underline{X}$ as that lower bound and to define $K^{\prime}$ as the number of subcontractors actually used, i.e, the value of $i$ that satisfies either (17) or (18). In Case $1, \underline{X}=Z_{K^{\prime}}(\mathrm{H})$; in Case $2, \underline{X}=x^{*}$. Note that

$$
K^{\prime}=\max \left\{i \mid \max \left\{Z_{i}(H), Z_{i}(L)\right\} \geq \underline{X}\right\}
$$

To summarize, the trajectory behaves as follows when $D=\mathrm{H}$ :

- If $x>Z_{0}(\mathrm{H})$, then $u_{0}=\underline{u}_{0}$ and $u_{j}=0$ for $j=1, \ldots, K$. $x$ decreases at rate $\underline{u}_{0}-\mu_{\mathrm{H}}$.

- If $Z_{i-1}(\mathrm{H})>x>Z_{i}(\mathrm{H})$ and $i<K^{\prime}$, for $j=1, \ldots, i \leq K$, then $u_{0}=\underline{u}_{0}, u_{j}=\underline{u}_{j}$ for $j=1, \ldots, i-1$, and $u_{j}=0$ for $j \geq i$. $x$ decreases at rate $\underline{u}_{0}+\underline{u}_{1}+\ldots+\underline{u}_{i-1}-\mu_{\mathrm{H}}$.

- If $Z_{K^{\prime}-1}(\mathrm{H})>x \geq Z_{K^{\prime}}(\mathrm{H})$ and $x$ is constant, then $u_{0}=\underline{u}_{0}, u_{j}=\underline{u}_{j}$ for $j=1, \ldots, K^{\prime}-1$,

$\star$ if $x=Z_{K^{\prime}}(\mathrm{H})$, then

$$
u_{K^{\prime}}^{*}=\mu_{\mathrm{H}}\left(1-B\left(Z_{K^{\prime}}(\mathrm{H})\right)\right)-\sum_{j=0}^{K^{\prime}-1} \underline{u}_{j} .
$$


$\star$ if $x=x^{*}$, then

$$
u_{K^{\prime}}=\underline{u}_{K^{\prime}} .
$$

and $u_{j}=0$ for $j=K^{\prime}+1, \ldots, K$.

\subsection{Characteristics of $Z_{j}(D)$}

So far, we know that

$$
Z_{0}(\mathrm{~L})>Z_{1}(\mathrm{~L})>Z_{2}(\mathrm{~L})>\ldots>Z_{K}(\mathrm{~L}),
$$

and, for the same reasons

$$
Z_{0}(\mathrm{H})>Z_{1}(\mathrm{H})>Z_{2}(\mathrm{H})>\ldots>Z_{K}(\mathrm{H}) .
$$

When $D=\mathrm{L}, x$ increases until it reaches $Z_{0}(\mathrm{~L})$, and it remains there until $D=\mathrm{H}$. After the change in demand, $x$ decreases until it reaches $\underline{X}$. We can therefore conclude that, for a steady-state probability distribution to exist,

$$
Z_{0}(\mathrm{~L}) \geq \underline{X}
$$

Since $\underline{X} \leq x \leq Z_{0}(\mathrm{~L})$, the objective function cannot be minimal if $\underline{X}>0$. In addition, since sales are lost when $x<0$, the objective function cannot be minimal if $Z_{0}(\mathrm{~L})<0$. Therefore

$$
Z_{0}(\mathrm{~L}) \geq 0 \geq \underline{X}
$$

\section{Analysis of the Model}

In this section, we calculate the steady-state probability distribution of $x$ and $D$ assuming that the system is operated under the policy of Section 4. In Section 6, we evaluate the expected profit (as well as other performance measures). Then we find the optimal policy by finding the values of $Z_{0}(\mathrm{H}), \ldots, Z_{K}(\mathrm{H}), Z_{0}(\mathrm{~L}), \ldots, Z_{K}(\mathrm{~L})$ that maximize the expected profit.

\subsection{Dynamics}

The analysis of even simple systems with general non-zero $B(x)$ results in non-closed form solutions. In order to treat a wide variety of backlog-dependent demand functions, it is convenient to assume that $B(x)$ is piecewise constant. That is,

$$
B(x)= \begin{cases}0 & x \geq 0 \\ B_{1} & 0>x \geq \beta_{1} \\ B_{i} & \beta_{i-1}>x \geq \beta_{i} \quad i=2, \ldots, M\end{cases}
$$




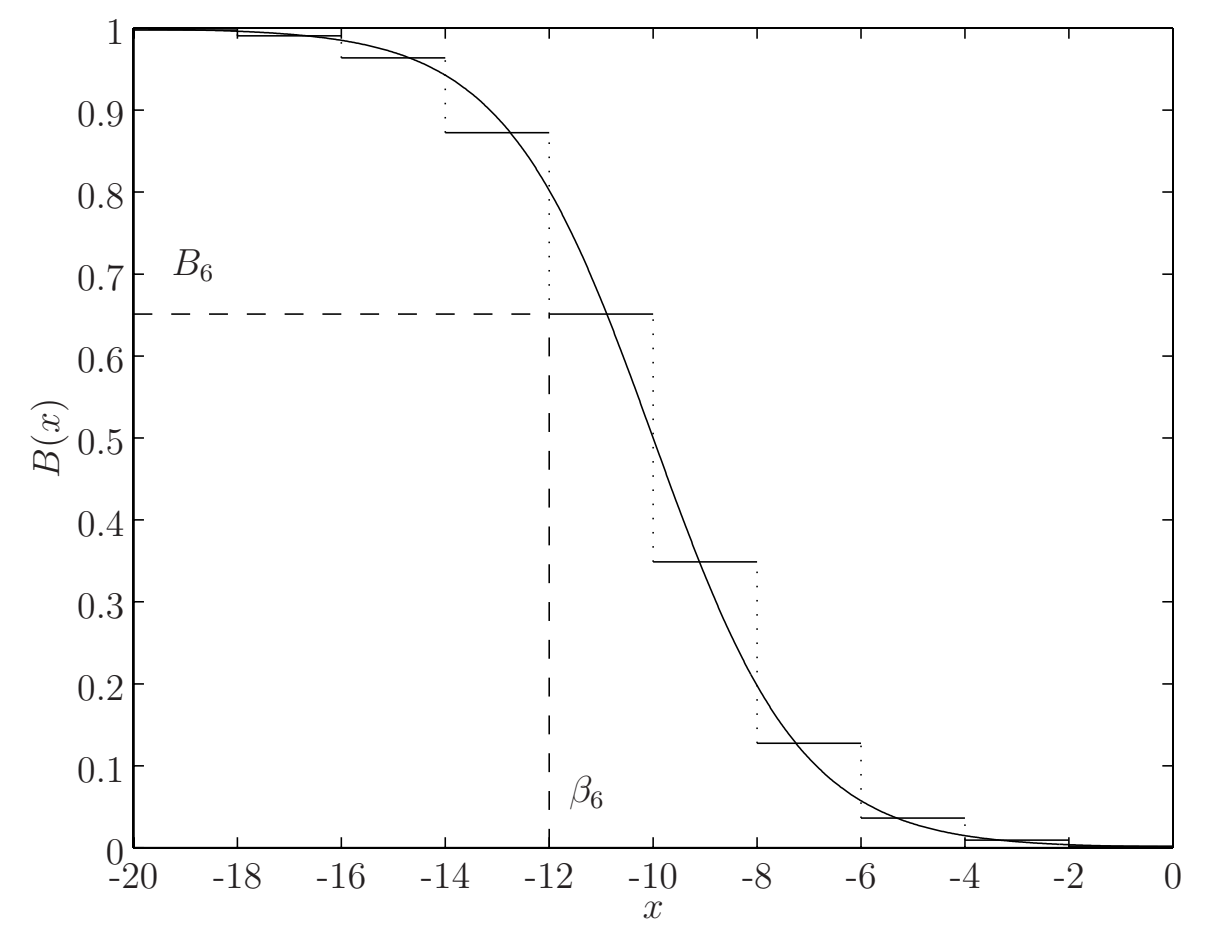

Figure 2: Step-wise constant approximation of a continuous $B(x)$ function

where $\beta_{i}, B_{i}, i=1, \ldots, M$ are constants. From (1) and (2),

$$
\begin{gathered}
0<B_{i}<B_{i+1} \leq 1 \\
0>\beta_{i}>\beta_{i+1} .
\end{gathered}
$$

By a proper choice of these constants, and for large enough $M$, any monotonic $B(x)$ can be arbitrarily closely approximated. Figure 2 shows a step-wise constant approximation of a continuous $B(x)$ function.

It is also convenient to assume that the $\beta_{i}$ and $B_{i}$ are chosen so that (18) can be satisfied exactly. That is, for each $i$ such that $Z_{i}(\mathrm{H})<0$, there is an $I(i)$ and a $B_{I(i)}$ such that

$$
\sum_{j=0}^{i} \underline{u}_{j}=\mu_{\mathrm{H}}\left(1-B_{I(i)}\right)
$$

When subcontracting and backlog-dependent demand are combined, the $x$ axis is divided into at most $2 K+M+4$ regions. Within each of these regions, the right side of the $x$ dynamics $(3)$ is constant and $g(x)$ is linear. Let

$$
R=\left\{Z_{i}(\mathrm{~L}) \mid i=0,1, \ldots, K\right\} \cup\left\{Z_{i}(\mathrm{H}) \mid i=0,1, \ldots, K\right\} \cup\{0\} \cup\left\{\beta_{i} \mid i=1, \ldots, M\right\} \cup\{\underline{X}\}
$$

and let $\|R\|+1$ be the number of unique elements in $R$. Assume $R$ is indexed in decreasing order, i.e., $R_{i}>R_{i+1}, i=0,1,2, \ldots,\|R\|-1 \leq 2 K+M+3$. Since $Z_{0}(\mathrm{~L})>0$ and $\beta_{i}<0$ for all $i$, 
- $R_{0}=Z_{0}(\mathrm{~L})>0$,

- $R_{\|R\|}<0$.

Let $\Delta_{i}^{\mathrm{L}}$ be the rate of change of $x$ in region $i$ when the demand state $D$ is low $(\mathrm{L})$. Then

$$
\Delta_{i}^{\mathrm{L}}=\sum_{j=0}^{K} u_{j}-\mu_{\mathrm{L}}(1-B(x)), R_{i}<x<R_{i+1}, i=0,1,2, \ldots\|R\|
$$

where $u_{j}, j=0,1, \ldots, K$ are given by (13). Recall that $u_{j}$ and $B(x)$ are all constant in each region, so $\Delta_{i}^{\mathrm{L}}$ is constant.

Similarly, let $\Delta_{i}^{\mathrm{H}}$ be the rate of change of $x$ in region $i$ when $D=\mathrm{H}$. Then

$$
\Delta_{i}^{\mathrm{H}}=\sum_{j=0}^{K} u_{j}-\mu_{\mathrm{H}}(1-B(x)), R_{i}<x<R_{i+1}, i=0,1,2, \ldots\|R\|
$$

where $u_{j}, j=0,1, \ldots, K$ are described in Section 4.3 .

As $x$ decreases, more subcontractor capacity is utilized. Furthermore, some of the potential customers choose not to order and this decreases the demand rate. As a result, when $D=\mathrm{H}, x$ decreases in region $i<J$ and increases in region $i \geq J$, where $J$ is uniquely defined as

$$
J=\min \left\{j \mid \Delta_{j}^{\mathrm{H}} \geq 0\right\}
$$

and the lower level is located at $R_{J}=\underline{X}$.

Figure 3 depicts the sample path of a system with three subcontractors $(K=3)$ and backorderdependent demand described by $\beta_{i}, B_{i}, i=1,2,3$. We assume that $\underline{u}_{0}+\underline{u}_{1}+\underline{u}_{2}<\mu_{\mathrm{H}}$, and $\underline{u}_{0}+\underline{u}_{1}+\underline{u}_{2}>\mu_{\mathrm{L}}$. That is, the low demand $\mu_{\mathrm{L}}$ can be met with the capacity of the factory and the two least expensive subcontractors, but the high demand $\mu_{\mathrm{H}}$ cannot. When demand is high $\left(d=\mu_{\mathrm{H}}\right), x(t)$ decreases and the slope, which starts steeply negative, increases to zero at $x=R_{6}$. When demand is low $\left(d=\mu_{\mathrm{L}}\right), x$ increases and the slope, which starts steeply positive, decreases to zero at $x=R_{0}=Z_{0}(\mathrm{~L})$. In this case the hedging levels are located at $R_{0}$ and $R_{6}$ and only two subcontractors are used. Furthermore, Regions 6 and 7 are transient.

Incorporating backlog-dependent demand into the model guarantees that $x$ is always bounded between $R_{0}$ and $R_{J}$. Even if the production capacity (including the additional capacity obtained from the subcontractors) is not sufficient to meet the average demand $E d$, the backlog-dependent demand of (3) yields a feasible equilibrium where a portion of the demand is matched with the available capacity and the remaining portion is lost. As a result, a steady state probability distribution always exists.

In the following sections, we describe how the optimal policy is determined. First, the system is evaluated by determining the probability density functions in the interior, and probability masses at the upper and lower levels for given values of $Z_{0}(\mathrm{~L}), Z_{1}(\mathrm{~L}), Z_{2}(\mathrm{~L}), \ldots, Z_{K^{\prime}}(\mathrm{L})$ and $Z_{0}(\mathrm{H}), Z_{1}(\mathrm{H}), Z_{2}(\mathrm{H}), \ldots, Z_{K^{\prime}}(\mathrm{H})$. Then, the optimal values of these parameters are determined by maximizing the expected profit. 


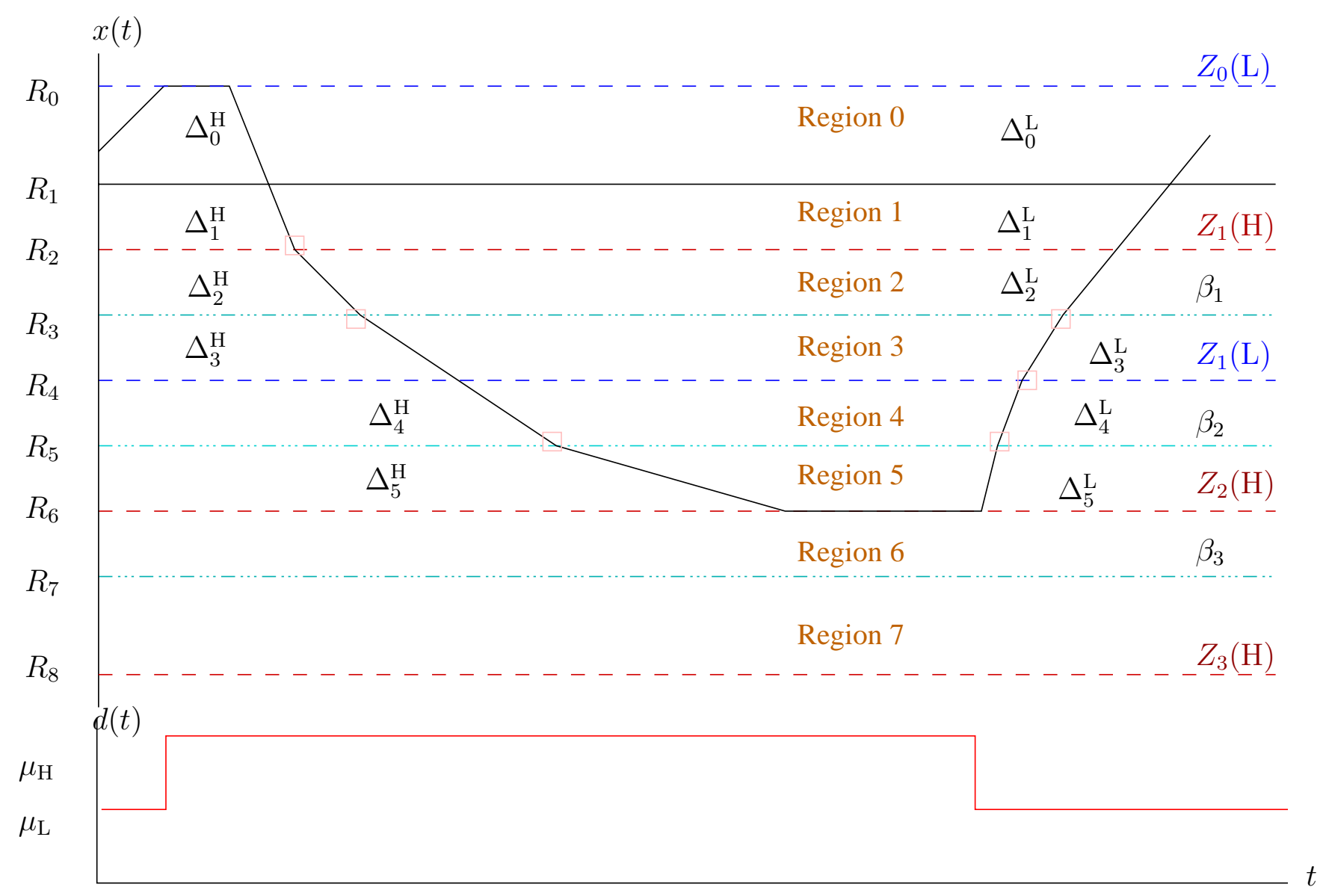

Figure 3: Sample paths for a system with three subcontractors and backorder-dependent demand 


\subsection{Probability distribution}

When the surplus/backlog $x$ is not equal to the upper or lower levels $\left(R_{0}\right.$ or $\left.R_{J}\right)$, the system is said to be in the interior. The system state at time $t$ is $S(t)=(x(t), D(t))$ where $R_{J}<x(t)<R_{0}$ and $D(t) \in\{\mathrm{H}, \mathrm{L}\}$.

The time-dependent system state probability distribution for the interior region, $F_{D}(t, x)$, is defined as

$$
F_{D}(t, x)=\operatorname{prob}[D(t)=D, x(t) \leq x], t \geq 0, D \in\{\mathrm{H}, \mathrm{L}\}, R_{J}<x(t)<R_{0} .
$$

The time-dependent system state density functions are defined as

$$
f_{D}(t, x)=\frac{\partial F_{D}(t, x)}{\partial x} t \geq 0, D \in\{\mathrm{H}, \mathrm{L}\}, R_{J}<x(t)<R_{0} .
$$

We assume that the process is ergodic and, thus, steady-state density functions exist. The steady-state density functions are defined as

$$
f_{D}(x)=\lim _{t \rightarrow \infty} f_{D}(t, x), \quad D \in\{\mathrm{H}, \mathrm{L}\}, R_{J}<x(t)<R_{0} .
$$

The steady-state probabilities that the finished goods inventory is equal to the hedging level $Z_{0}(\mathrm{~L})$ and the lowest level $\underline{X}$ are denoted by $P^{0}$ and $P^{J}$.

Let us also define $P_{i}^{\mathrm{H}}$ and $P_{i}^{\mathrm{L}}, i=0,1 \ldots, J-1$, as the probabilities that the process is in region $i$ in the long run when the demand is high and when it is low, respectively:

$$
\begin{aligned}
& P_{i}^{D}=\lim _{t \rightarrow \infty} \operatorname{prob}\left[R_{i}<x(t)<R_{i+1}, D(t)=D\right] \\
& =\int_{R_{i+1}}^{R_{i}} f_{D}(x) d x \quad D \in\{\mathrm{H}, \mathrm{L}\}, i=0, \ldots, J-1 .
\end{aligned}
$$

In order to derive the differential equations that describe the behavior of the system in internal regions, first suppose that $R_{i+1}<x(t+\delta t)<R_{i}, i=1,2, \ldots, J-1$, and $D(t+\delta t)=\mathrm{H}$. Then, since we are modeling this system as a Markov process,

$$
f_{\mathrm{H}}(t+\delta t, x)=f_{\mathrm{H}}\left(t, x-\Delta_{i}^{\mathrm{H}} \delta t\right)\left(1-\lambda_{\mathrm{HL}} \delta t\right)+f_{\mathrm{L}}(t, x)\left(\lambda_{\mathrm{LH}} \delta t\right)+o(\delta t)
$$

where $\mathrm{o}(\delta t)$ approaches to zero faster than $\delta t$. This equation can be written in differential form, for $\delta t \rightarrow 0$, as

$$
\frac{\partial f_{\mathrm{H}}(t, x)}{\partial t}+\Delta_{i}^{\mathrm{H}} \frac{\partial f_{\mathrm{H}}(t, x)}{\partial x}=-\lambda_{\mathrm{HL}} f_{\mathrm{H}}(t, x)+\lambda_{\mathrm{LH}} f_{\mathrm{L}}(t, x)
$$

Taking the limit of $(28)$ as $t \rightarrow \infty$ yields the following steady-state differential equation for $f_{\mathrm{H}}(x)$ :

$$
\Delta_{i}^{\mathrm{H}} \frac{d f_{\mathrm{H}}(x)}{d x}=-\lambda_{\mathrm{HL}} f_{\mathrm{H}}(x)+\lambda_{\mathrm{LH}} f_{\mathrm{L}}(x), \quad R_{i+1}<x<R_{i}
$$


Following the same steps for $f_{\mathrm{L}}$ yields

$$
\Delta_{i}^{\mathrm{L}} \frac{d f_{\mathrm{L}}(x)}{d x}=\lambda_{\mathrm{HL}} f_{\mathrm{H}}(x)-\lambda_{\mathrm{LH}} f_{\mathrm{L}}(x) R_{i+1}<x<R_{i}
$$

\section{Solution of the Model}

\subsection{Probability Distribution}

The differential equations (29)-(30) are solved to determine the probability density functions and the probability masses for the upper and lower levels by using a level crossing analysis. We report the complete solution in this section. For the detailed derivation of the solution, the reader is referred to (Tan and Gershwin 2001).

Let $c_{i}, i=0,1,2, \ldots,\|R\|$ be the coefficients used in the solution of $f_{\mathrm{H}}(x)$ and $f_{\mathrm{L}}(x)$. The first coefficient $c_{0}$ is given by

$$
c_{0}=\left[\frac{\left(\mu_{\mathrm{H}}-u_{0}\right) e^{\eta_{0} R_{0}}}{\lambda_{\mathrm{LH}}}+\sum_{i=0}^{J-1} \phi_{i} \frac{\left(\Delta_{i}^{\mathrm{L}}-\Delta_{i}^{\mathrm{H}}\right)}{\Delta_{i}^{\mathrm{L}}} X_{i}-\frac{\phi_{J-1} \Delta_{J-1}^{\mathrm{H}} e^{\eta_{J-1} R_{J}}}{\lambda_{\mathrm{HL}}}\right]^{-1}
$$

where

$$
X_{i}= \begin{cases}\left(e^{\eta_{i} R_{i}}-e^{\eta_{i} R_{i+1}}\right) / \eta_{i} & \text { if } \eta_{i} \neq 0 \\ \left(R_{i}-R_{i+1}\right) & \text { if } \eta_{i}=0\end{cases}
$$

and

$$
\phi_{i}=\prod_{j=1}^{i-1} \frac{\Delta_{j-1}^{\mathrm{H}}}{\Delta_{j}^{\mathrm{H}}} e^{\left(\eta_{j-1}-\eta_{j}\right) R_{j}}, i=1, \ldots, J-1 .
$$

Furthermore, $c_{i}=\phi_{i} c_{0}, i=1,2, \ldots,\|R\|$. Then the solution for $f_{\mathrm{H}}(x)$ and $f_{\mathrm{L}}(x)$ are

$$
\begin{gathered}
f_{\mathrm{H}}(x)=c_{i} e^{\eta_{i} x}, \quad R_{i+1}<x<R_{i} \\
f_{\mathrm{L}}(x)=-c_{i} \frac{\Delta_{i}^{\mathrm{H}}}{\Delta_{i}^{\mathrm{L}}} e^{\eta_{i} x}, \quad R_{i+1}<x<R_{i}
\end{gathered}
$$

where

$$
\eta_{i}=-\frac{\lambda_{\mathrm{HL}}}{\Delta_{i}^{\mathrm{H}}}-\frac{\lambda_{\mathrm{LH}}}{\Delta_{i}^{\mathrm{L}}} .
$$

The steady-state probabilities $P^{0}$ and $P^{J}$ are

$$
\begin{gathered}
P^{0}=\lim _{t \rightarrow \infty} \operatorname{prob}\left[x(t)=R_{0}\right]=-c_{0} \frac{\Delta_{0}^{\mathrm{H}}}{\lambda_{\mathrm{LH}}} e^{\eta_{0} R_{0}} \cdot, \\
P^{J}=\lim _{t \rightarrow \infty} \operatorname{prob}\left[x(t)=R_{J}\right]=-c_{J-1} \frac{\Delta_{J-1}^{\mathrm{H}}}{\lambda_{\mathrm{HL}}} e^{\eta_{J-1} R_{J}} .
\end{gathered}
$$




\subsection{Evaluation of the Objective Function}

In order to determine the optimal values of the hedging levels, the profit must be evaluated. Let $\Pi_{i}$ be the total profit rate generated through production at source $i, i=0,1, \ldots, K^{\prime}$. The profit generated by the plant, $\Pi_{0}$ is determined by using the optimal production rate given in equation (12) as

$$
\Pi_{0}=\lim _{T \rightarrow \infty} E\left[\frac{1}{T} \int_{0}^{T} A_{0} u_{0} d \tau\right]=A_{0}\left(\operatorname{prob}\left[x<R_{0}\right] \underline{u}_{0}+\operatorname{prob}\left[x=R_{0}\right] \mu_{L}\right)
$$

which can be simplified as

$$
\Pi_{0}=A_{0}\left(1-c_{0} \frac{\left(\underline{u}_{0}-\mu_{\mathrm{L}}\right)\left(\mu_{\mathrm{H}}-\underline{u}_{0}\right)}{\lambda_{\mathrm{LH}}} e^{\eta_{0} R_{0}}\right)
$$

The fraction of time subcontractor $i, i=1,2, \ldots, K^{\prime}-1$ is used, denoted by $\Upsilon_{i}$, can be written as

$$
\Upsilon_{i}=\left[P^{J} I_{\left\{Z_{i}(\mathrm{H})>R_{J}\right\}}+\sum_{j=1}^{J-1}\left(P_{i}^{\mathrm{H}} I_{\left\{Z_{i}(\mathrm{H})>R_{j}\right\}}+P_{i}^{\mathrm{L}} I_{\left\{Z_{i}(\mathrm{~L})>R_{j}\right\}}\right)\right]
$$

where $I_{\left\{Z_{i}(\mathrm{H}) \geq R_{J}\right\}}=1$ if $Z_{i}(\mathrm{H}) \geq R_{J}$ and 0 otherwise. Note that the manufacturing plant is always used, i.e, $\Upsilon_{0}=1$.

Then, the total profit rate generated through production at subcontractor $i, i=1,2, \ldots, K^{\prime}-1$ is

$$
\Pi_{i}=A_{i} \underline{u}_{i} \Upsilon_{i}
$$

The term for the profit obtained from the last subcontractor depends on whether the lower level is determined by the subcontractor hedging level or by the customer behavior. If it is determined by the subcontractor hedging level then the last subcontractor provides goods at a rate which is sufficient to keep $x$ at this lower level as discussed in Section 4.3. Otherwise, the last subcontractor provides goods at its maximum rate. Then, the profit obtained from subcontractor $K^{\prime}$ can be written as

$$
\Pi_{K}^{\prime}=A_{K^{\prime}} \underline{u}_{K^{\prime}}\left[P^{J} I_{\left\{Z_{K^{\prime}}(\mathrm{H})>R_{J}\right\}}+\sum_{j=1}^{J-1}\left(P_{K^{\prime}}^{\mathrm{H}} I_{\left\{Z_{K^{\prime}}(\mathrm{H})>R_{j}\right\}}+P_{K^{\prime}}^{\mathrm{L}} I_{\left\{Z_{K^{\prime}}(\mathrm{L})>R_{j}\right\}}\right)\right]+A_{K^{\prime}} u_{K^{\prime}}^{*} P^{J} I_{\left\{Z_{K^{\prime}}(\mathrm{H})=R_{J}\right\}}
$$

The second term in equation (4) reflects the inventory carrying costs. Let $\Psi_{i}$ be defined as

$$
\Psi_{i}=\int_{R_{i}+1}^{R_{i}} x\left(f_{H}(x)+f_{L}(x)\right) d x=c_{i} \frac{\Delta_{i}^{\mathrm{L}}-\Delta_{i}^{\mathrm{H}}}{\Delta_{i}^{\mathrm{L}}} Q_{i}
$$

where 


$$
Q_{i}= \begin{cases}\left(\left(\eta_{i} R_{i}-1\right) e^{\eta_{i} R_{i}}-\left(\eta_{i} R_{i+1}-1\right) e^{\eta_{i} R_{i+1}}\right) / \eta_{i}^{2} & \text { if } \eta_{i} \neq 0 \\ \left(R_{i}^{2}-R_{i+1}^{2}\right) / 2 & \text { if } \eta_{i}=0\end{cases}
$$

Let $i_{0}$ be the index of the region boundary at $x=0$ :

$$
i_{0}=\left\{j \mid R_{j}=0\right\}
$$

Then the average inventory level $E_{\text {WIP }}$ is

$$
E_{\mathrm{WIP}}=\sum_{j=0}^{i_{0}-1} \Psi_{j}+R_{0} P^{0}
$$

Finally, the average profit per unit time is

$$
\Pi=\sum_{i=0}^{K^{\prime}} \Pi_{i}-g^{+} E_{\mathrm{WIP}}
$$

The optimal values of $Z_{0}(\mathrm{~L}), Z_{1}(\mathrm{~L}), Z_{2}(\mathrm{~L}), \ldots, Z_{K^{\prime}}(\mathrm{L})$ and $Z_{0}(\mathrm{H}), Z_{1}(\mathrm{H}), Z_{2}(\mathrm{H}), \ldots, Z_{K^{\prime}}(\mathrm{H})$ are determined by maximizing $\Pi$. In the numerical studies, the simplex search of Nelder and Mead (1965) is used to determine the optimal threshold values efficiently.

\subsection{Other Performance Measures}

We can also evaluate other quantities of interest. The average sales rate or throughput rate is

$T H=P^{0} \mu_{\mathrm{L}}+\sum_{i=0}^{K^{\prime}} \underline{v}_{i}\left[P^{J} I_{\left\{Z_{i}(\mathrm{H}) \geq R_{J}\right\}}+\sum_{j=1}^{J-1}\left(P_{i}^{\mathrm{H}} I_{\left\{Z_{i}(\mathrm{H})>R_{j}\right\}}+P_{i}^{\mathrm{L}} I_{\left\{Z_{i}(\mathrm{~L})>R_{j}\right\}}\right)\right]+\left(u_{K^{\prime}}^{*}-\underline{v}_{K^{\prime}}\right) P^{J} I_{\left\{Z_{K^{\prime}}(\mathrm{H})=R_{J}\right\}}$

The service level, the ratio of the average sales to the average demand, is

$$
S=T H / E d
$$

The fill rate is the probability that a customer receives his product as soon as he arrives:

$$
F R=\operatorname{prob}[x>0]=P^{0}+\sum_{i=0}^{i_{0}-1}\left(P_{i}^{\mathrm{H}}+P_{i}^{\mathrm{L}}\right)
$$

The average backlog level is $E_{\mathrm{BL}}$ which is evaluated as

$$
E_{\mathrm{BL}}=-\sum_{j=i_{0}}^{J-1} \Psi_{j}-R_{J} P^{J}
$$

The behavior of the model and the sensitivity of these performance measures on the system parameters such as demand variability, customer defection function, inventory carrying cost, and subcontractors price are investigated through numerical experiments. A limited number of cases is given below. The reader is referred to (Tan and Gershwin 2001) for other numerical results. 

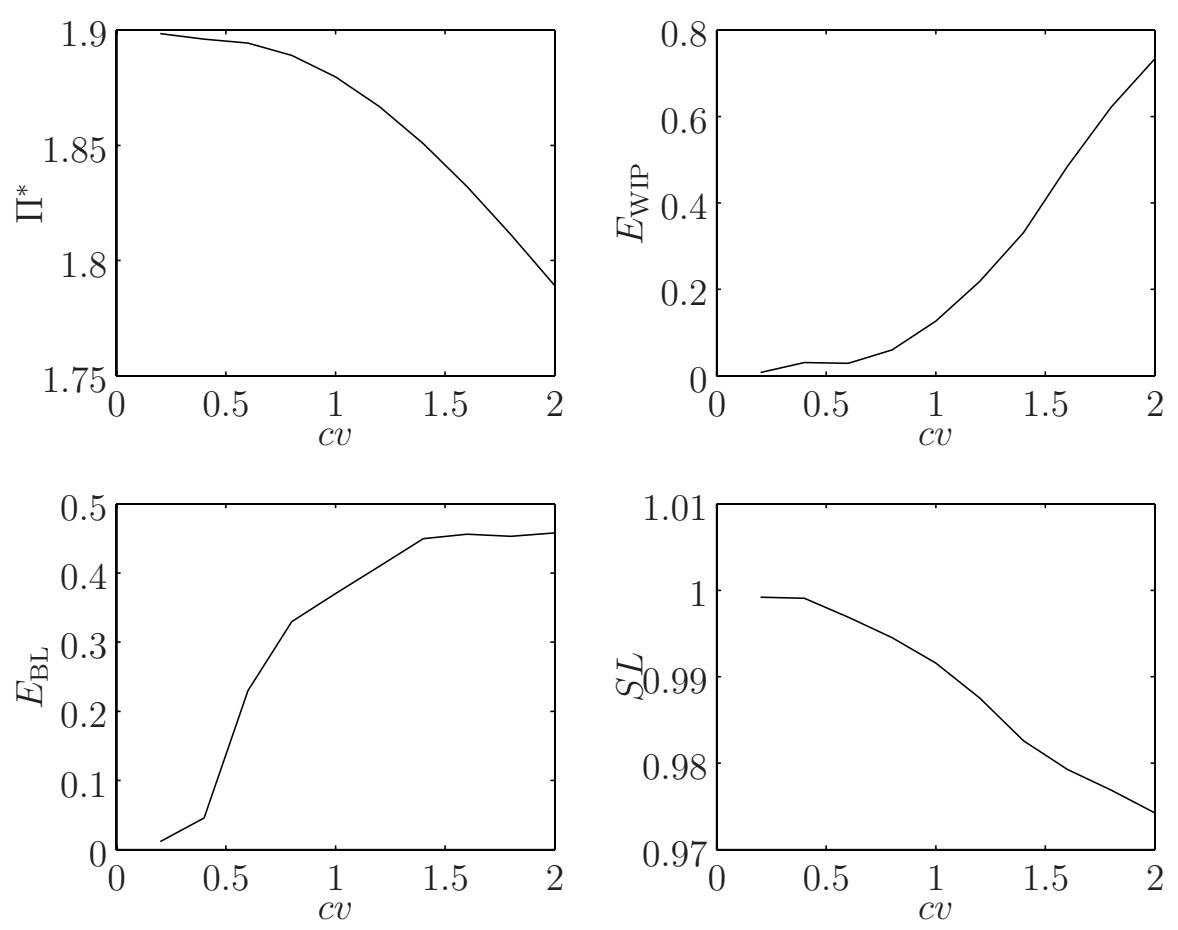

Figure 4: Effect of the demand variability $\left(\mu_{\mathrm{H}}=1.5, \mu_{\mathrm{L}}=0.3, E d=0.9, \underline{u}_{0}=0.5, \underline{u}_{1}=0.9, A_{0}=3\right.$, $\left.A_{1}=1, g^{+}=0.1, \chi=-4, M=20, \gamma=0.5\right)$

\section{Behavior of the Model}

\subsection{Effect of Demand Variability}

The effect of the variability of demand on the performance of the system is depicted in Figure 4 for a system consisted of a plant and a subcontractor. In the following examples, a customer defection function of the form $B(x)=\frac{1}{1+e^{\gamma(x-\chi)}}$ is assumed. In the discretization of $B(x)$, we let the step size be $\delta=\frac{1}{M \gamma} \ln \left[\frac{\epsilon}{1-\epsilon}+\chi\right]$ in order to reach $1-\epsilon$ in $M$ steps $(\epsilon=0.001)$ :

$$
\left.\begin{array}{rl}
\beta_{i} & =-\delta i \\
B_{i} & =\frac{1}{2}\left(\frac{1}{1+e^{\gamma\left(\beta_{i-1}-\chi\right)}}+\frac{1}{1+e^{\gamma\left(\beta_{i}-\chi\right)}}\right)
\end{array}\right\} i=1,2, . ., M .
$$

The variability of demand is indicated by the coefficient of variation of the demand rate $c v$. In the numerical examples, $\lambda_{\mathrm{HL}}$ and $\lambda_{\mathrm{LH}}$ are set according to the desired $c v$ while keeping $e=\frac{\lambda_{\mathrm{LH}}}{\lambda_{\mathrm{HL}}+\lambda_{\mathrm{LH}}}$ the same.

Figure 4 shows that, as the demand variability increases, the profit and service level decrease and the average backlog and the average inventory increase. 


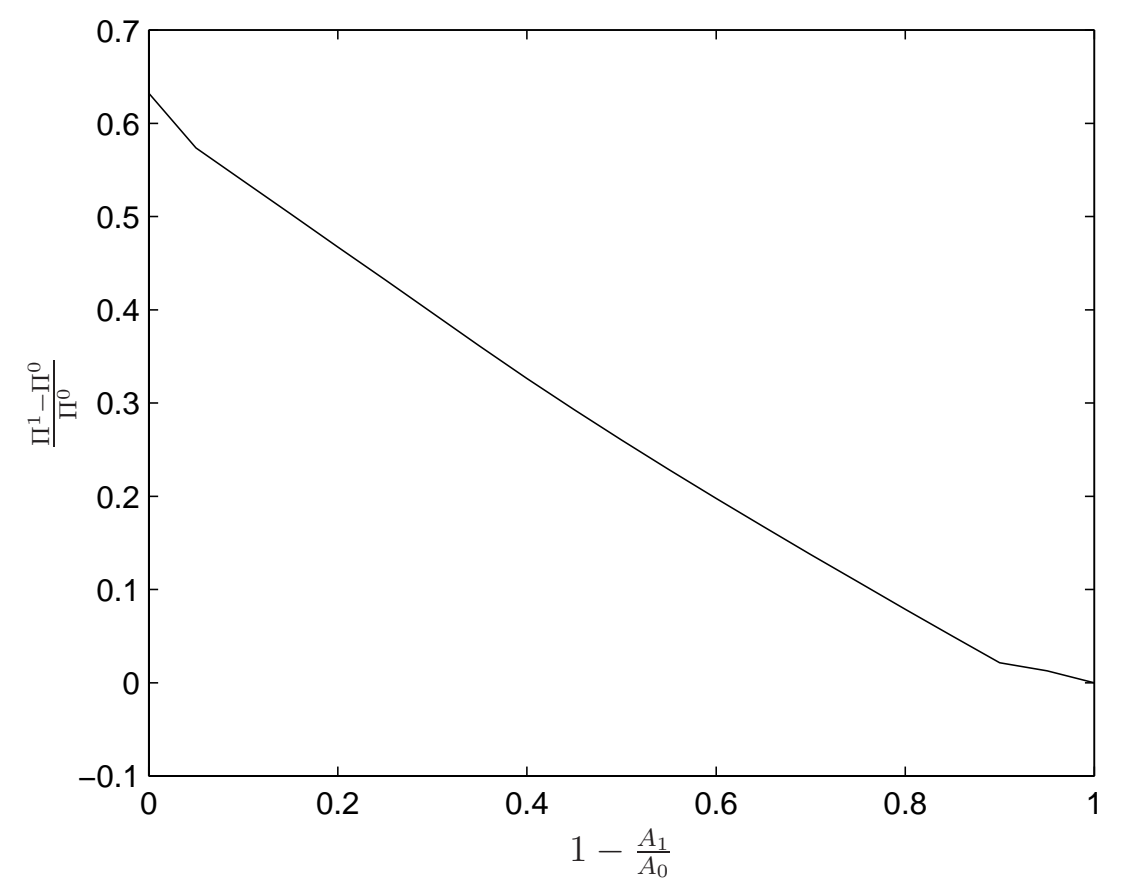

Figure 5: Effect of the subcontracting price $\left(\mu_{\mathrm{H}}=1.5, \mu_{\mathrm{L}}=0.3, \lambda_{\mathrm{HL}}=0.1, \lambda_{\mathrm{LH}}=0.1, \underline{u}_{0}=0.6\right.$, $\left.\underline{u}_{1}=1 A_{0}=3, g^{+}=0.1, \chi=-3, M=10, \gamma=0.5\right)$

\subsection{Effect of a Subcontractor's Price}

Figure 5 shows the effect of the price per unit that a single subcontractor charges. If the final sales price of the item is $\pi$ per unit, the cost for making it in-house is $\pi-A_{0}$ per unit (other than inventory cost), and the price charged by the subcontractor is $\pi-A_{1}$. A measure of the additional subcontractor cost relative to $A_{0}$, which is independent of final product sales price, is therefore $\left(A_{0}-A_{1}\right) / A_{0}$, the horizontal axis of Figure 5 . When this ratio is close to 0 , the subcontractor cost is low; when it is close to 1 , the price is high.

The vertical axis of Figure 5 is the fractional increase in optimal profits as a result of making use of the subcontractor. The total profit for the case where no subcontracting is used is denoted by $\Pi^{0}$ and the total profit for the case where the subcontractor is available is denoted by $\Pi^{1}$. When the profit from to the subcontractor's supplies is very small compared to the profit from using the manufacturing facility, i.e. when $1-A_{1} / A_{0}$ is close to 1 , the subcontractor is used very little and therefore there is little profit gain. However, as the profit due to the subcontractor approaches the profit from the manufacturing facility, i.e., as $1-A_{1} / A_{0}$ approaches 0 , the subcontracting increases the total profit substantially, as much as $63 \%$.

Having a subcontractor always available allows the manufacturer to reduce backlog and therefore customer loss. Furthermore, since the subcontractor is used when it is necessary and only paid for the volume of production received, this agreement is attractive for the manufacturer. In order to make this agreement more attractive for the subcontractor, the contractual agreement may 
include a fixed up-front payment for the duration of the agreement. Tan (2002a) analyzes this kind of agreement as an option by using a producer with one subcontractor and backlog independent demand. An option is the right, but not obligation, to take an action in the future and a real option is one in which real (non-financial) assets are involved. Since the contractual agreement is related to increasing the capacity, we refer this option as a capacity option. Tan and Gershwin (2001) provides additional numerical examples for evaluating the terms of a capacity option for the model studied here. These studies show that the additional costs associated with using a more expensive subcontractor can be justified when the demand variability high. In this case, additional production costs of the subcontractors are lower than the cost of holding inventory and the opportunity cost of lost sales.

\subsection{An Approximate Subcontracting Policy}

The optimal feedback policy derived in this study is a function of the inventory/surplus $x$ and the demand state $D$. Although the inventory/surplus can be observed easily, the demand state may not be observable. Therefore, an approximate policy that does not depend on the demand state may be necessary. In particular, setting $Z_{i}(\mathrm{H})=Z_{i}(\mathrm{~L})=Z_{i}$ yields an approximate policy that does not depend on the demand state. We call this approximation the demand-insensitive policy.

Moreover, as $\lambda_{\mathrm{HL}}$ and $\lambda_{\mathrm{LH}}$ approach infinity, i.e. as the demand state switches faster between high and low, incorporating the demand information in the feedback policy provides less value. Having different levels for each demand state can be beneficial only when the demand persists in a given state, that is, when the demand variability is high.

Figure 6 depicts the profits for a system with a manufacturing facility and two subcontractors for the optimal and the demand-insensitive policies denoted by $\Pi$ and $\Pi_{S}$ respectively as the demand variability changes for the same $e$. The figure shows that when the demand variability is low, both policies give the same profit. Even when the demand variability is high, the difference between the optimal profit and the near-optimal profit is less than $1.5 \%$.

\subsection{Waiting Time for a Customer}

An important performance measure of the system is $W$, the waiting time for a customer. In this section we derive expressions for the expected waiting time and also the minimum and maximum of the waiting time for a customer who arrives when the backlog is $x$.

\subsubsection{Expected waiting time}

In order to derive the expected waiting time, $T H$ can be written as

$$
T H=T H^{+} \operatorname{prob}[x \geq 0]+T H^{-} \operatorname{prob}[x<0]
$$

where $\mathrm{TH}^{+}$and $\mathrm{TH}^{-}$are the conditional throughput rates when $x \geq 0$ and $x<0$ respectively. Since all the demand can be satisfied when $x \geq 0, T H^{+}$is equal to $E d^{+}$, the conditional average demand rate when $x \geq 0$, which can be evaluated as 


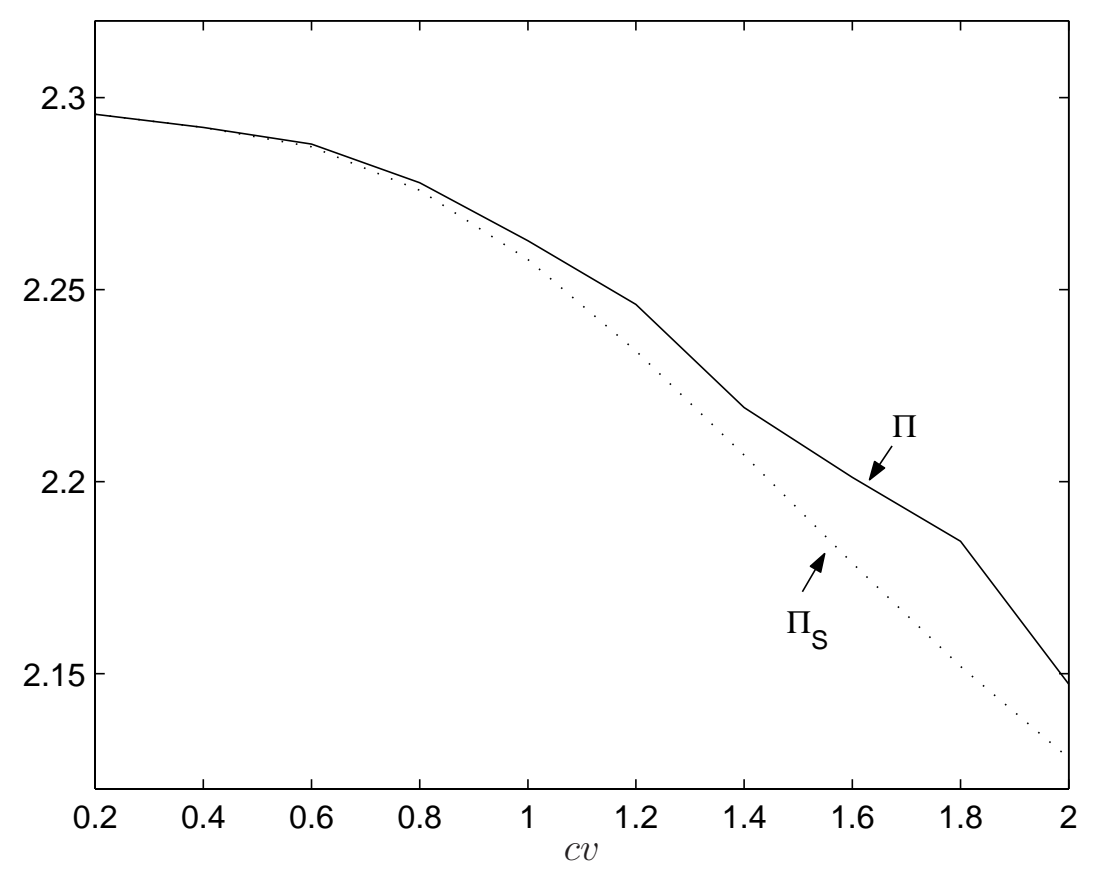

Figure 6: Value comparison for the demand-insensitive policy $\left(\mu_{\mathrm{H}}=1.5, \mu_{\mathrm{L}}=0.3, E d=0.9\right.$, $\left.\underline{u}_{0}=0.5, \underline{u}_{1}=0.8, \underline{u}_{2}=1, A_{0}=3, A_{1}=2, A_{2}=1, g^{+}=0.1, \chi=-3, M=10, \gamma=0.5\right)$ 


$$
E d^{+}=T H^{+}=\frac{1}{F R}\left(\mu_{L} P^{0}+\sum_{j=0}^{i_{0}-1}\left(\mu_{H} P_{i}^{\mathrm{H}}+\mu_{L} P_{i}^{\mathrm{L}}\right)\right)
$$

Then the expected waiting time $E[W]$ is

$$
E[W]=(1-F R) \frac{E_{\mathrm{BL}}}{T H^{-}}
$$

where $\mathrm{TH}^{-}$is determined from equations (48) and (49).

\subsubsection{Bounds on waiting time}

In order to derive the bounds for the waiting time, the demand rate is set to its minimum and maximum and the resulting dynamics are solved deterministically. The maximum waiting time of a customer who arrives when there is a backlog of $\underline{x}$ is determined by the very conservative assumption that all new customers will arrive at rate $\mu_{\mathrm{L}}$. Let $y(t)$ be the amount of remaining work in front of a customer who has joined at $t=0$ when the backlog is $y(0)=\underline{x}$. Then the following set of differential equations determine the maximum waiting time $W_{\mathrm{MAX}}$ :

$$
\begin{gathered}
\frac{d y}{d t}=u^{*}(x, \mathrm{~L})+\sum_{i=1}^{K} u_{i}^{*}(x, \mathrm{~L}), y(0)=\underline{x} \\
\frac{d x}{d t}=u^{*}(x, \mathrm{~L})+\sum_{i=1}^{K} u_{i}^{*}(x, \mathrm{~L})-\mu_{\mathrm{L}}(1-B(x)), x(0)=\underline{x} \\
W_{\text {MAX }}(\underline{x})=\min \{t \mid y(t)=0\}
\end{gathered}
$$

Similarly, the minimal waiting time is determined by the assumption that all new customers will arrive at rate $\mu_{\mathrm{H}}$. In this case, the minimum waiting time $W_{\mathrm{MIN}}$ is determined by the following equations:

$$
\begin{gathered}
\frac{d y}{d t}=u^{*}(x, \mathrm{H})+\sum_{i=1}^{K} u_{i}^{*}(x, \mathrm{H}), y(0)=\underline{x} \\
\frac{d x}{d t}=u^{*}(x, \mathrm{H})+\sum_{i=1}^{K} u_{i}^{*}(x, \mathrm{H})-\mu_{\mathrm{H}}(1-B(x)), x(0)=\underline{x} \\
W_{\mathrm{MIN}}(\underline{x})=\min \{t \mid y(t)=0\}
\end{gathered}
$$

Figure 7 shows $W_{\text {MIN }}$ and $W_{\text {MAX }}$ for four different cases. In all the cases, the upper line depicts $W_{\text {MAX }}$ and the lower one depicts $W_{\text {MIN }}$. In the first case (a), there is a single manufacturing facility and there are no subcontractors. In this case, the waiting time for a customer who arrives when the backlog is $x$ is $x / \underline{u}_{0}$, and $W_{\mathrm{MIN}}=W_{\mathrm{MAX}}=x / \underline{u}_{0}$. 
(a) $K=0$

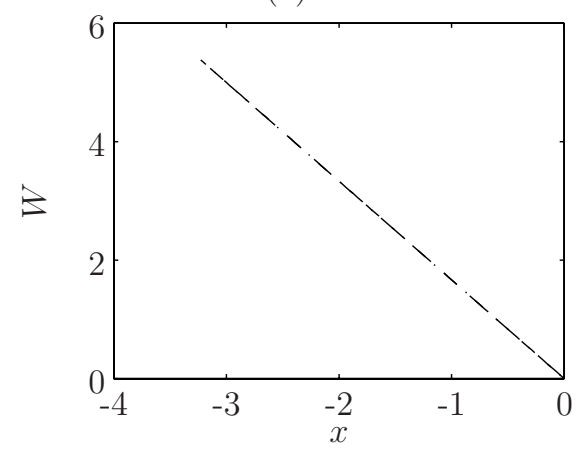

(c) $K=1$

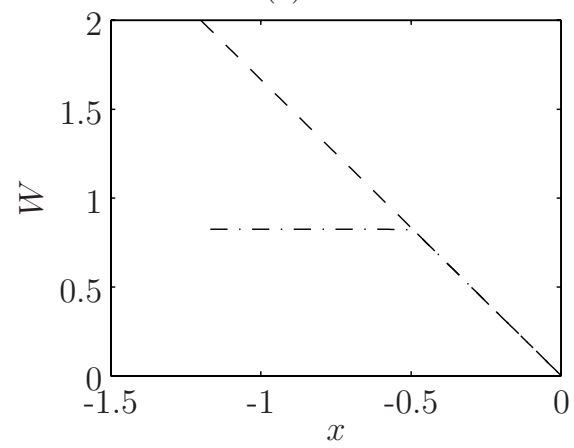

(b) $K=1$

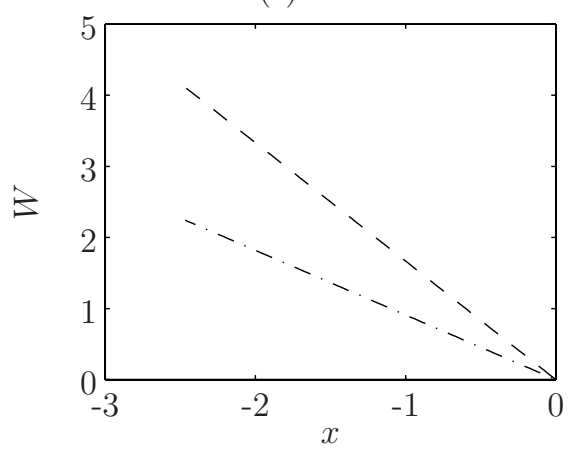

(d) $K=2$

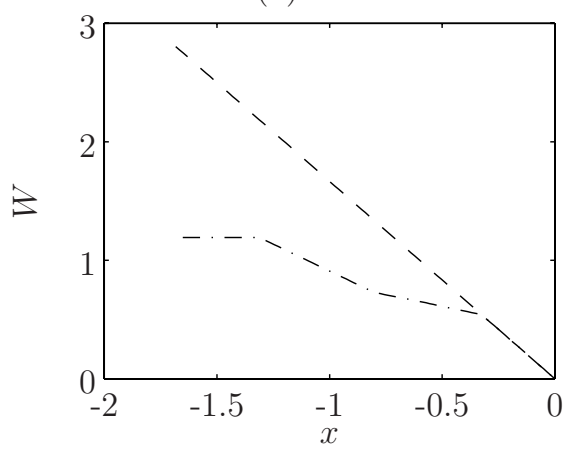

Figure 7: $W_{\mathrm{MIN}}$ and $W_{\mathrm{MAX}}$ for four different cases $\left(\mu_{\mathrm{H}}=1.5, \mu_{\mathrm{L}}=0.3, \lambda_{\mathrm{HL}}=0.05, \lambda_{\mathrm{LH}}=0.05\right.$, $g^{+}=0.1, \chi=-3, M=10, \gamma=0.5,(\mathrm{a}): \underline{u}_{0}=0.6, A_{0}=3,(\mathrm{~b}): \underline{u}_{0}=0.6, \underline{u}_{1}=0.5, A_{0}=3, A_{1}=2$, (c): $\underline{u}_{0}=0.6, \underline{u}_{1}=1, A_{0}=3, A_{1}=1,(\mathrm{~d}): \underline{u}_{0}=0.6, \underline{u}_{1}=0.51, \underline{u}_{2}=1, A_{0}=10, A_{1}=6, A_{2}=5$.)

In the second case (b), there is one manufacturing facility and one subcontractor. The subcontractor is used when $X \leq x<0$ and $D=\mathrm{H}$ and it is not used when $\underline{X} \leq x<0$ and $D=\mathrm{L}$. In this specific case, $W_{\mathrm{MIN}}=x /\left(\underline{u}_{0}+\underline{u}_{1}\right)$ and $W_{\mathrm{MAX}}=x / \underline{u}_{0}$.

In the third case (c), there is also a manufacturing facility and a subcontractor. However, due to different system parameters, $Z_{1}(\mathrm{H})<0$. In this case, when $x$ is close to zero, $W_{\text {MIN }}=W_{\text {MAX }}=x / \underline{u}_{0}$. Note that $W_{\text {MIN }}$ and $W_{\text {MAX }}$ are not equal when $x$ is sufficiently negative. The fourth case (d) depicts a similar picture for a system with one manufacturing plant and two subcontractors.

\section{Conclusions}

We have extended the widely-studied dynamic programming model of real-time scheduling control of manufacturing systems in three important ways: we model the effect of backlog on profits through an explicit representation of customer behavior; we model the availability of subcontractors to provide finished goods when the factory's short-term capacity is insufficient; and we model random demand.

We use the Bellman equation to determine a solution structure, and we find that the solution 
involves a hedging point (to limit how far production should be allowed to go ahead of demand), and a set of thresholds (that indicate when to use each of the subcontractors). To calculate the hedging point and the thresholds, we find the steady-state probability distribution. We evaluate the objective function and choose values of the parameters to maximize it.

Finally, we have performed a set of numerical experiments to demonstrate the behavior of the new model and the solution.

This research can be extended in several different directions: An extension of the hedging point policy to complex systems (multiple part types; multiple stages; general routing including reentrant flow) is described by Gershwin (2000). In the present system, lead time is due only to the producer falling behind demand. In the more complex system, lead time is also due to the fact that material flows from stage to stage, and may have to wait at each stage. The policy in (Gershwin 2000) is based on a dynamic programming problem that includes an explicit backlog cost and no subcontractors. It would be of interest to replace that backlog cost with the present model of customer behavior and subcontractors (or equivalently spare capacity that is expensive to use).

To make the model more complete, we should include possible delays in subcontractor performance. Another extension would be to guarantee lead times to customers, but this may require creating classes, one for each guaranteed lead time.

\section{Acknowledgments}

We are grateful for support from the TUBITAK-NATO Science Fellowship program, the National Science Foundation, Grant DMI-9713500, the Lean Aircraft Initiative, and the Xerox Foundation. We also thank the members of the Harvard Center for Textile and Apparel Research for the many interesting and helpful discussions. We also thank the anonymous referees for their insightful remarks.

\section{References}

Abernathy, F. H., J. T. Dunlop, J. H. Hammond, and D. Weil (1999). A Stich in Time: Lean retailing and the transformation of manufacturing-lessons from the apparel and textile industries. Oxford University Press, New York.

Abernathy, F. H., J. T. Dunlop, J. H. Hammond, and D. Weil (2000). Control your inventory in a world of lean retailing. Harvard Business Review November-December, 169-176.

Bielecki, T. and P. R. Kumar (1988). Optimality of zero-inventory policies for unreliable manufacturing systems. Operations Research 36(4), 532-541.

Bradley, J. (1999). Optimal control of an M/M/1 subcontracting model. Technical report, Cornell University.

Bradley, J. and P. Glynn (2000a). Managing capacity and inventory effectively in manufacturing systems. Technical report, Cornell University. 
Bradley, J. and P. Glynn (2000b). Managing the manufacturer-subcontractor relationship and the manufacturer's optimal capacity, inventory, and subcontracting policies. Technical report, Cornell University.

Fleming, W., S. Sethi, and H. Soner (1987). An optimal stochastic production planning with randomly fluctuating demand. SIAM Journal of Control Optimization 25, 1495-1502.

Fukuda, Y. (1964). Optimal policies for the inventory problem with negotiable lead-time. Management Science 4, 690-708.

Gershwin, S. and B. Tan (2001). Production control with backlog-dependent demand. unpublished manuscript.

Gershwin, S. B. (1992-1993). Extension of FMS scheduling model. Unpublished note.

Gershwin, S. B. (1994). Manufacturing Systems Engineering. Prentice-Hall. See http://web.mit.edu/manuf-sys/www/gershwin.errata.html for corrections.

Gershwin, S. B. (2000). Design and operation of manufacturing systems - the control-point policy. IIE Transactions 32(2), 93-103.

Ghosh, M., A. Araposthathis, and S. Markus (1993). Optimal control of switching diffusions with applications to flexible manufacturing systems. SIAM Journal of Control Optimization 31, 1183-1204.

$\mathrm{Hu}$, J. (1995). Production rate control for failure prone production with no backlog permitted. IEEE Transactions on Automatic Control 40(2), 291-295.

Huang, L., J. Hu, and P. Vakili (1999, May 16-20). Optimal control of a multi-state manufacturing system: Control of production rate and temporary increase in capacity. Second Aegean International Conference on Analysis and Modeling of Manufacturing Systems, 191198. http://www.samos.aegean.gr/icsd/secaic/.

Kimemia, J. G. and S. B. Gershwin (1983). An algorithm for the computer control of production in a flexible manufacturing systems. IIE Transactions 15(4), 353-362. Reprinted in Modeling and Control of Automated Manufacturing Systems by Alan A. Desrochers, IEEE Computer Society Press Tutorial, 1990.

Krichagina, E. V., S. X. C. Lou, and M. I. Taksar (1994). Double band policy for stochastic manufacturing systems in heavy traffic. Mathematics of Operations Research 19(3), 560-597.

Nelder, J. and R. Mead (1965). A simplex method for function minimization. Computer Journal 7, 308-313.

Olsder, G. J. and R. Suri (1980, December). Time-optimal control of flexible manufacturing systems with failure prone machines. In Proceedings of the 19th IEEE Conference on Decision and Control, Albuquerque, New Mexico.

Perkins, J. and R. Srikant (2001). Failure-prone production systems with uncertain demand. IEEE Transactions on Automatic Control. to appear.

Puzo, M. (1969). The Godfather. G.P. Putnam's Sons. 
Schweppe, F., M. Caramanis, R. Tabors, and R. Bohn (1988). Spot Pricing of Electricity. Kluwer Academic Publishers, Boston.

Sethi, S. P. and G. L. Thompson (2000). Optimal Control Theory: Applications to Management Science and Economics (2 ed.). Kluwer Academic Publishers, the Netherlands.

Tan, B. (1997). Variance of the throughput of an $N$-station production line with no intermediate buffers and time dependent failures. European Journal of Operational Research 101(3), 560576 .

Tan, B. (2002a). Managing manufacturing risks by using capacity options. Journal of the Operations Research Society 53(2), 232-242.

Tan, B. (2002b). Production control of a pull system with production and demand uncertainty. IEEE Transactions on Automatic Control 47(5), 779-783.

Tan, B. and S. B. Gershwin (2001). On production and subcontracting strategies for manufacturers with limited capacity and volatile demand. Working Paper Series ORC 354-01, Massachusetts Institute of Technology, Operations Research Center.

Van Mieghem, J. A. (1999). Coordinating investment, production, and subcontracting. Management Science 45(7), 954-971.

Whittemore, A. and S. Saunders (1977). Optimal inventory under stochastic demand with two supply options. SIAM Journal of Applied Mathematics 32, 293-305.

Yan, H., S. Lou, S. Sethi, A. Gardel, and P. Deosthali (1996, May). Testing the robustness of two-boundary control policies in semiconductor manufacturing. IEEE Transactions on Semiconductor Manufacturing 9(2), 285-288.

Zhang, V. (1995). Ordering Policies for an Inventory System with Supply Flexibility. Department of industrial engineering and engineering management ph. d. thesis, Stanford University. 